\title{
LOW-TEMPERATURE HEAT CONDUCTION IN PURE, MONOGRYSTALLINE ICE
}

\author{
By J. KLINGER* \\ (Laboratoire de Spectromćtrie Physique, Domaine Universitaire, B.P. 53, F 3804 I-Grenoble \\ Cedex, France, and Service des Basses Températures, Centre d'Études Nucléaires, B.P. 85 , \\ $\mathrm{F}_{3} 8 \mathrm{o} 4 \mathrm{I}$-Grenoble Cedex, France)
}

\begin{abstract}
The heat conduction of ice single crystals is measured by a steady-state heat-flux method between $1.7 \mathrm{~K}$ and $100 \mathrm{~K}$. For temperatures higher than $16 \mathrm{~K}$ all experimental points are found to be on the same curve. For temperatures lower than $16 \mathrm{~K}$ the heat conduction curves depend on the material of the crystallization vessel, the ageing of the sample and the cooling rate between the temperature of the mount $\left(\approx_{260 \mathrm{~K}}\right)$ and liquid-nitrogen temperature. No anisotropy can be found for temperatures higher than $9 \mathrm{~K}$. Computer fits are made, based on Callaway's model of heat conduction in dielectric crystals. An attempt is made to explain the observed extrinsic heat conduction by the presence of microstructures in ice. It is shown that heat-conduction measurements can be used to establish a "quality-list" of samples studied in laboratories.

RÉsumé. Conduction thermique à basse température dans la glace pure monocristalline. La conduction thermique de monocristaux de glace est mesurée par la méthode du flux de chaleur stationnaire entre $1,7 \mathrm{~K}$ et $100 \mathrm{~K}$. Pour des températures supérieures à $16 \mathrm{~K}$ tous les points expérimentaux se trouvent sur une courbe unique. Pour des températures inférieures à $16 \mathrm{~K}$ les courbes de conduction thermiques dépendent du matériau du vase de cristallisation, du vieillissement de l'échantillon et de la vitesse de refroidissement entre la témpérature du montage $(\approx 260 \mathrm{~K})$ et la température de l'azote liquide. Aucune anisotropie ne peut être trouvée pour des températures supérieures à $9 \mathrm{~K}$. Des ajustements sur ordinateur ont été effectues basés sur le modèle de la conduction thermique des isolants de Callaway. Une tentative d'explication de la conduction thermique extrinsèque est donnée faisant intervenir des microstructures de la glace. Il est démontré qu'il est possible d'établir un cahier des charges des échantillons de glace étudiés aux laboratoires à partir de mesures de la conduction thermique.

Zusammenfassung. Wärmeleitung in reinem, monokristallinem Eis bei tiefen Temperaturen. Die thermische Leitfähigkeit von Eis-Einkristallen wurde mittels der Methode des stationären Wärmeflusses zwischen 1.7 K und 1oo K gemessen. Für Temperaturen oberhalb $16 \mathrm{~K}$ liegen alle Messpunkte auf einer Kurve. Unterhalb $16 \mathrm{~K}$ hängen die Wärmeleitfähigkeitskurven ab vom Material des Kristallisationsgefässes, der Alterung der Probe und der Abkühlgeschwindigkeit zwischen der Montagetemperatur $(\approx 260 \mathrm{~K})$ und der Temperatur des flüssigen Stickstoffs. Oberhalb von $9 \mathrm{~K}$ kann keinerlei Anisotropie festgestellt werden. Computerfits auf der Basis des Callawayschen Models der Wärmeleitfähigkeit dielektrischer Kristalle wurden erstellt. Ein Versuch wird unternommen, die extrinsische Wärmeleitfähigkeit mittels des Vorhandenseins von Mikrostrukturen im Eis zu erklären. Es wird gezeigt, dass es möglich ist, mittels Wärmeleitfähigkeitsmessungen eine Standardisierung von im Laboratorium studierten Eisproben zu erreichen.
\end{abstract}

\section{INTRODUCTION}

Thermal conductivity measurements in solids at low temperatures can give information about defects in the crystalline structure as shown by Klemens (1958) and Carruthers (196I). In particular such measurements on single crystals of ice can tell us about the influence of thermal or mechanical treatment on defects in the ice lattice. In this way it will be possible to standardize ice samples studied in laboratories. Such a standardization does not exist hitherto but is necessary in order to obtain more reproducible results in many domains of ice physics. Thus thermal conductivity measurements at very low temperatures can provide interesting information for glaciologists even though such temperatures are not found in natural ice sheets.

\section{EXPERIMENTAL PROCEDURE}

We use single crystals grown by a modified Bridgman method as described by Blicks (unpublished). A cylindrical teflon (polytetrafluorethylene) or plexiglas (polymethylmethacrylate) vessel is filled with water. The water we use is demineralized and doubledistilled under a nitrogen atmosphere in quartz vessels. We fix a seed crystal at the bottom France.

* Present address: Laboratoire de Glaciologie du C.N.R.S., 2, rue Très Cloîtres, F3803i Grenoble Cedex, 
of the crystallization vessel and lower this device at a rate of $1.2 \mathrm{~cm}$ a day into a bath of cold ethanol at $248 \mathrm{~K}$.

Activation analyses by Mme Echevin from the Laboratoire de Glaciologie at Grenoble showed the following concentrations of impurities present in a crystal grown in a teflon vessel:

$\mathrm{Mg}:(0.156 \pm 0.006) \mathrm{mg} / \mathrm{kg}$,

$\mathrm{Cl}:(0.2 \mathrm{I} 4 \pm 0.004) \mathrm{mg} / \mathrm{kg}$,

$\mathrm{Mn}$ : (o.00I $23 \pm 0.000$ or) $\mathrm{mg} / \mathrm{kg}$,

$\mathrm{Na}:(0.027 \mathrm{I} \pm 0.0003) \mathrm{mg} / \mathrm{kg}$.

Analyses with a mass spectrometer by Mme Merlivat from the Centre d'Études Nucléaires at Saclay showed that the average concentration of deuterium in the same crystal is $14^{2.2 \pm}$ 0.05) $\mathrm{mg} / \mathrm{kg}$.

Thermal conductivity measurements have been done using the stationary heat-flow method. A known heating power $P$ goes through the sample. Knowing the length $\Delta X$ and the cross-section of the sample $S$ we can determine the thermal conductivity $\lambda$ using Fourier's law:

$$
\lambda(T)=\frac{P \Delta X}{\left(T_{2}-T_{1}\right) S}
$$

where $T_{2}-T_{\mathrm{I}}$ is the temperature difference between the ends of the sample.

The mean temperature of the sample can be chosen by means of a thermal resistance between the sample and the cryogenic bath and a second heating device.

The main difficulties of heat-conduction measurements on ice at low temperatures are the sample mounting and cooling down to liquid-nitrogen temperature, since ice samples are very fragile, and the thermal expansion coefficient is very different for ice and copper (we used a copper sample holder). We covered our samples with a film of Apiezon C oil in order to avoid thermal cracking. In this way we were able to measure thermal conductivities between $1.7 \mathrm{~K}$ and $\mathrm{r} 6 \mathrm{o} \mathrm{K}$. The rate of cooling from the mounting temperature $(\approx 260 \mathrm{~K})$ to liquid-nitrogen temperature was $0.6 \mathrm{~K} / \mathrm{min}$ (exceptionally $\mathrm{r} .2 \mathrm{~K} / \mathrm{min}$ ).

Experimental error on the absolute value of the thermal conductivity was lower than $15 \%$ from 1.7 to $7 \mathrm{~K}$ and lower than $12 \%$ for higher temperatures. As the calibration error of the thermometer was $3 \%$ the relative error between independent curves of thermal conductivity was 9 to $12 \%$. Within one curve we can disregard the error on the dimension of the sample so that the relative error within one curve is lower than $7 \%$.

The sample mean temperature could be measured with an error lower than $4 \%$, arising mainly from thermometer calibration.

When the crystallographic orientation of the sample is not mentioned the heat flux was parallel to the $c$-axis.

\section{Results}

Figure I to 5 show results on thermal conductivity measurements on samples of pure ice.

In Figure I we compare the heat-conduction curves of two identical ice samples cut from the centre of the same crystal grown in a teflon vessel. The results of former authors found in the literature are indicated too. Lees (1905), Jakob and Erk (1929), Powell (1958), Dean and Timmerhaus (1962), Ratcliffe (r962), and Dillard and Timmerhaus ( 1965 ) give little information about the crystals used, but their method of sample preparation leads to the conclusion that they measured polycrystals. Landauer and Plumb (1956) used single crystals. It is not quite clear whether Ashworth (unpublished) used single crystals. 


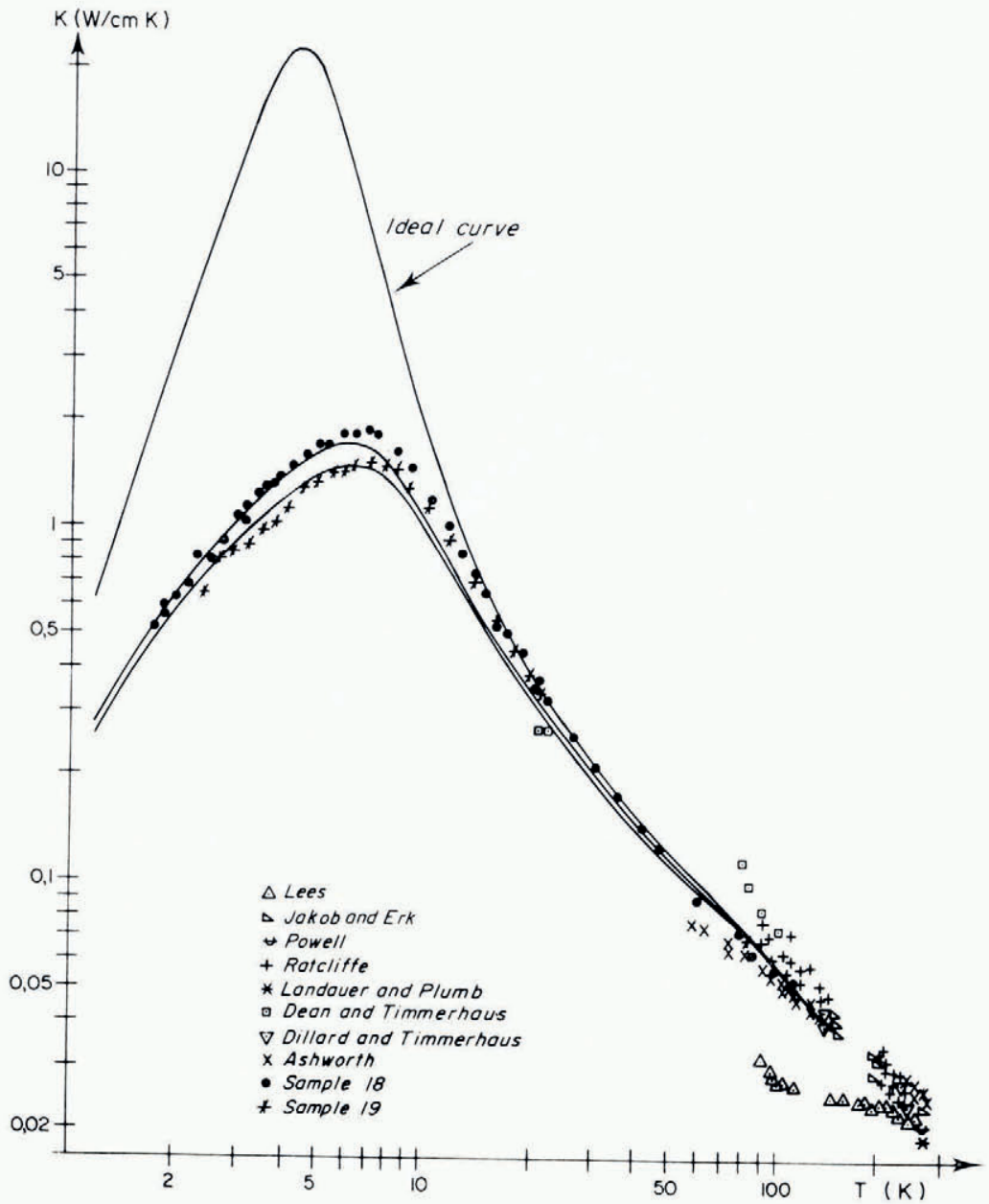

Fig. 1. Heat-conduction curves of identical samples cut from one crystal grown in a teflon vessel (this work) compared the results of former authors. Solid curves correspond to computer fits using the following parameters:

$$
\begin{aligned}
\text { lowest curve: } G_{\mathrm{d}}=2.67 \times 10^{-30} \mathrm{~s}^{2}, & R=3 ; \\
\text { middle curve: } G_{\mathrm{d}}=2.18 \times 10^{-30} \mathrm{~s}^{2}, & R=3 ; \\
\text { "ideal" curve: } G_{\mathrm{d}}=o, & R=0 .
\end{aligned}
$$

The solid curves correspond to computer fits discussed later. Near the maximum $(T \approx 7 \mathrm{~K})$ the difference between the conductivity values of sample 18 and 19 is about $15 \%$. This difference decreases for lower temperatures. For temperatures higher than $16 \mathrm{~K}$, curves $\mathrm{I} 8$ and 19 are identical and can be extrapolated to temperatures higher than roo $\mathrm{K}$ using the points of Dillard and Timmerhaus (1965), Jakob and Erk (1929), and Ashworth (1972).

Figure 2 shows the heat-conduction curve of a sample grown in a plexiglas vessel (sample 21, white points), compared with a sample grown in a teflon vessel (sample 18 , black points). The maximum is lower for the first one. The two curves are identical for temperatures higher than Io K.

Figure 3 shows the heat-conduction curve of a sample cut parallel to the $c$-axis (sample $2 \mathrm{I}$, white points) compared with the curves of samples cut perpendicular to the $c$-axis (sample 5 , 


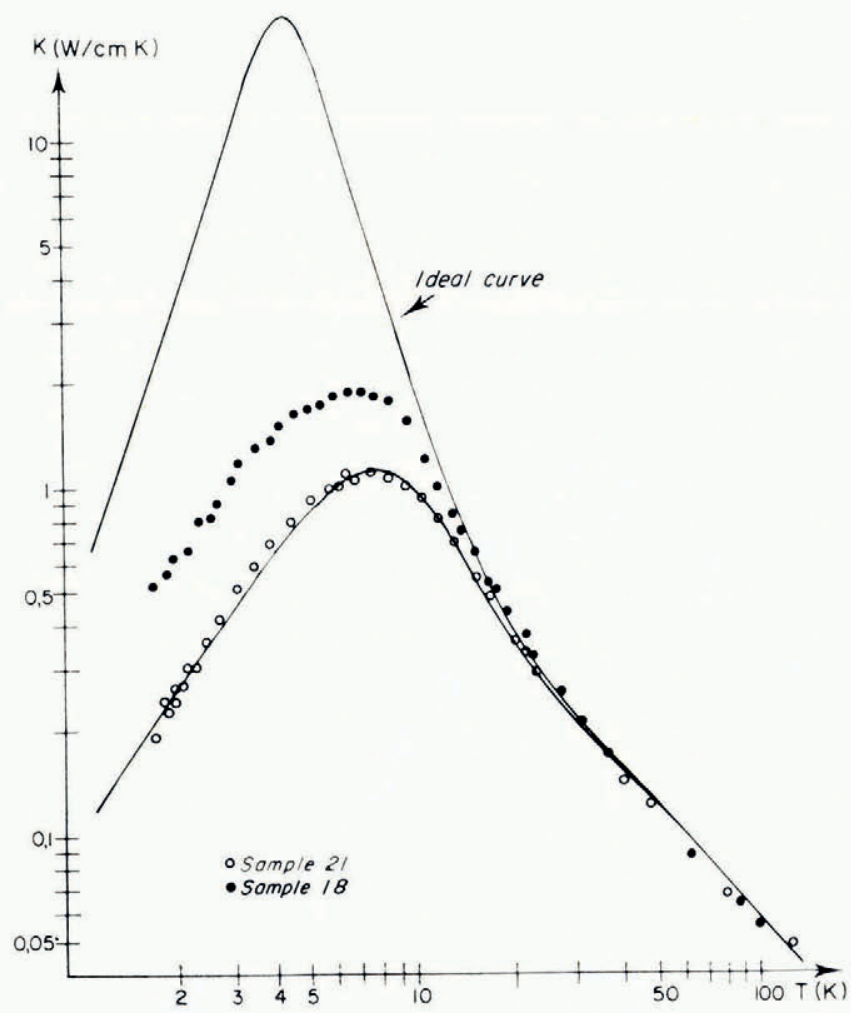

Fig. 2. Heat-conduction curves of samples grown in different vessels. Lower curve: sample grown in a plexiglas vessel; higher curve: sample grown in a teflon vessel. Solid lines correspond to computer fits: $\begin{array}{rlrl}\text { lower line: } G_{\mathrm{d}} & =6.4 \times 10^{-18} s, & R & =2 ; \\ \text { "ideal" curve: } G_{\mathrm{d}} & =0, & R & R .\end{array}$

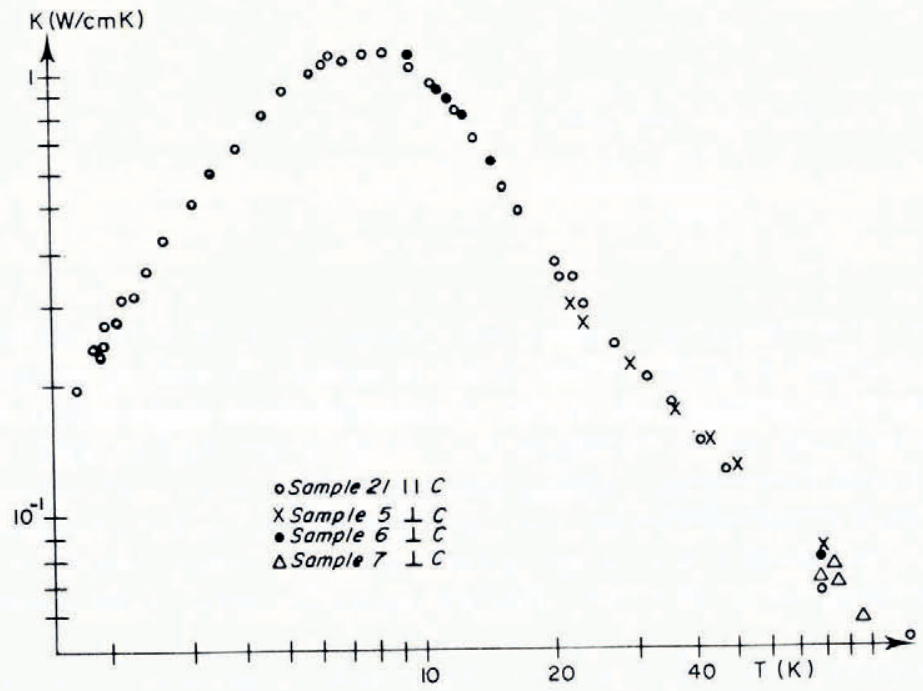

Fig. 3. Heat-conduction curves of samples with different orientations. Samples were grown in plexiglas vessels. 


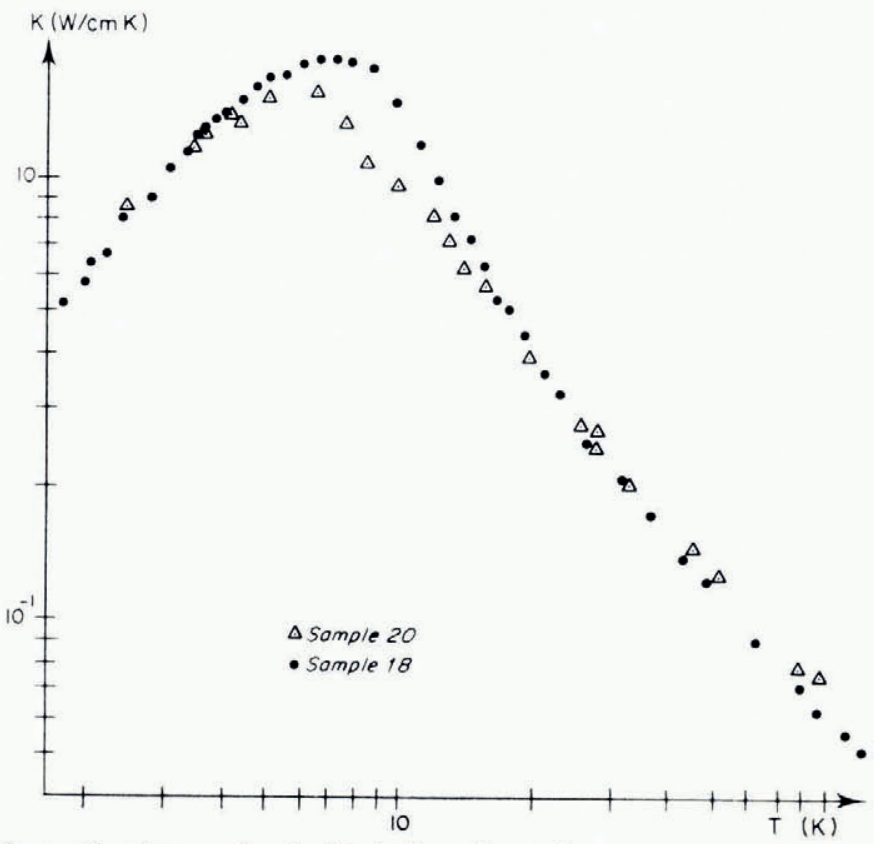

Fig. 4. Influence of ageing on otherwise identical samples cut from one crystal grown in a teflon vessel.

Lower curve: aged sample;

higher curve: fresh sample.

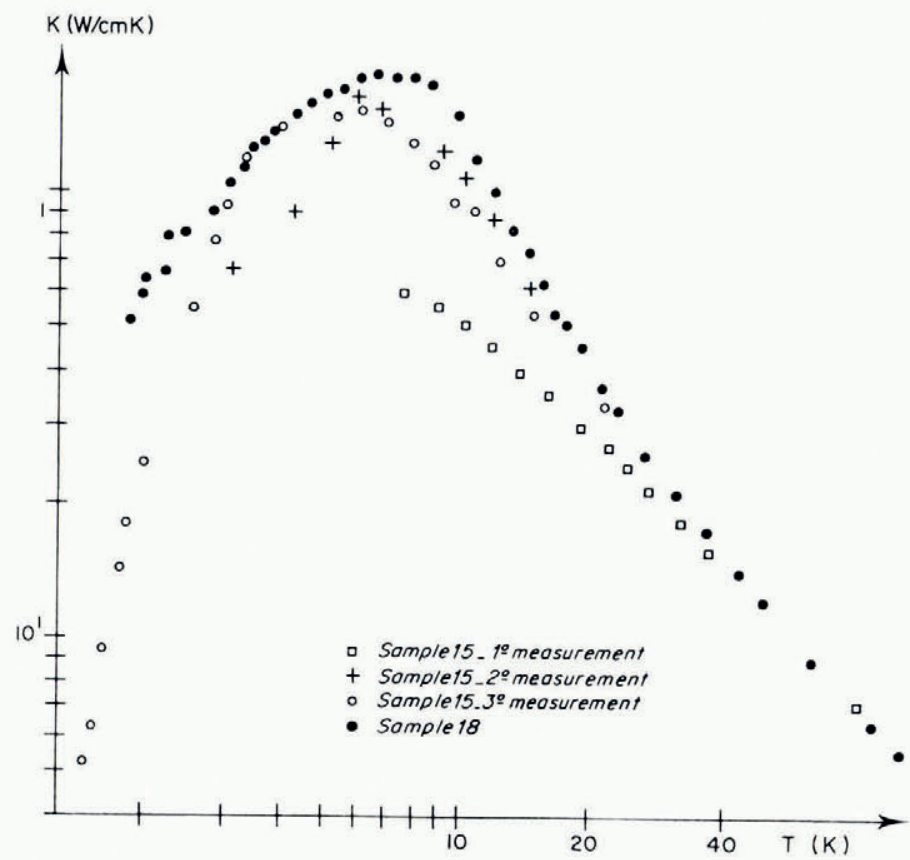

Fig. 5. Influence of cooling rate and annealing on a sample grown in a plexiglas vessel. Lowest curve: sample cooled at $I .2 \mathrm{~K} /$ min; middle curves: same sample after annealing and cooling at $0.6 \mathrm{~K} / \mathrm{min}$; highest curve: freshly grown sample 18 grown in a teflon vessel cooled $0.6 \mathrm{~K} / \mathrm{min}$. 
St Andrew's cross; sample 6, black points; sample 7, triangles). All these samples have been grown in plexiglas vessels. To the right of the maximum there is no visible anisotropy. It is not possible to confirm or to refute the anisotropy of $5 \%$ found by Landauer and Plumb ( 1056 ) at $268 \mathrm{~K}$ as our measurements do not cover this temperature.

Figure 4 shows the influence of ageing: two samples cut from the centre of the same crystal grown in a teflon vessel have been measured. One has been measured immediately after growth (sample 18 ), the other after ageing (sample 20) during nine months at $248 \pm 5 \mathrm{~K}$. Low- and high-temperature parts of the curves are identical. For temperatures close to the maximum, on the right side, the heat conduction is lower for the aged crystal.

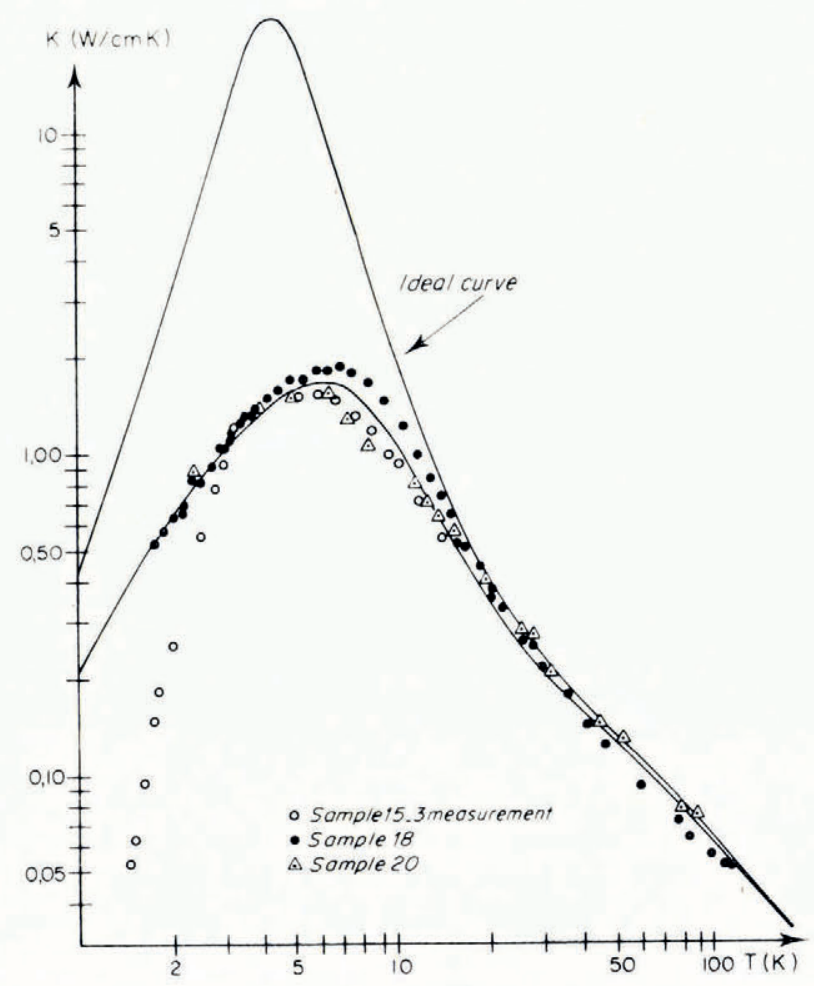

Fig. 6. Superposition of the heat-conduction curves of sample $I_{5}$ (third measurement annealed after rapid cooling) and sample 20 (aged). The solid curves corresponds to computer fits:

$$
\begin{array}{ll}
\text { lower curve: } G_{\mathrm{d}}=2.34 \times 10^{-30} s^{2}, & R=3 ; \\
\text { "ideal" curve: } G_{\mathrm{d}}=o, & R=o .
\end{array}
$$

Figure 5 shows the influence of the cooling rate on a sample grown in a plexiglas vessel (sample 15). The heat conduction curve of a sample cooled with a rate of $1.2 \mathrm{~K} / \mathrm{min}$ is very much lower than the curve of a fresh sample cooled at $0.6 \mathrm{~K} / \mathrm{min}$. After annealing of about one month at $27 \mathrm{I} \pm 0.5 \mathrm{~K}$ the second conductivity curve is higher. After another annealing of one year at $24^{8} \pm 5 \mathrm{~K}$ the high-temperature part of the heat-conduction curve is identical to the preceeding one. For temperatures higher than $3 \mathrm{~K}$ the curve is identical to these of a crystal grown in a teflon vessel and aged for nine months (sample 20, see Figure 6). The heat conduction in the low-temperature region falls very steeply $\left(\propto T^{5}\right)$. 
Qualitatively we can conclude the following:

The heat conduction curves presented in this work are identical for temperatures higher than $16 \mathrm{~K}$.

The heat conduction curves presented in this work have a maximum near $7 \mathrm{~K}$. curve.

For temperatures lower than $16 \mathrm{~K}$ each sample has its individual heat conduction

We conclude that the temperature range $>\mathrm{I} 6 \mathrm{~K}$ should be the "intrinsic" range where the thermal resistance is due to three phonon processes of the umklapp type (Carruthers, I96I). The range $<\mathrm{I} 6 \mathrm{~K}$ should be the "extrinsic" range where interactions of phonons with lattice imperfections are the dominant resistive mechanisms.

\section{Theory of heat conduction}

If we consider the phonon gas in a crystal as an ideal gas we may describe the thermal conductivity by means of the elementary relation:

$$
\lambda=\frac{1}{3} L c_{v} v \rho,
$$

where $L$ is the phonon mean free path, $v$ the mean velocity of sound, $c_{v}$ the specific heat capacity and $\rho$ the density.

If we define a relaxation time $\tau$, this equation may be rewritten:

$$
\lambda=\frac{1}{3} \tau v^{2} c_{v} \rho .
$$

By using Debye's approximation for the specific heat we obtain:

$$
\lambda_{\mathrm{I}}=\frac{k T^{3}}{2 \pi^{2} v}\left(\frac{k}{h}\right)^{3} \int_{0}^{\Theta / T} \tau x^{4} \mathrm{e}^{x}\left(\mathrm{e}^{x}-\mathrm{I}\right)^{-2} \mathrm{~d} x,
$$

where $x=\hbar \omega / k T, k$ is Boltzmann's constant, $2 \pi \hbar$ is Planck's constant, and $\Theta$ is the Debye temperature.

The total relaxation time is calculated by using the equation

$$
\tau^{-\mathrm{I}}=\sum_{i=1}^{n} \tau_{i}^{-\mathrm{I}}
$$

Where the $\tau_{i}$ are the relaxation times corresponding to different phonon interaction mechanisms. Callaway (I959) includes the relaxation time of normal processes in the total relaxation time $\tau$. As the normal processes are not really resistive but contribute to resistive processes only by a redistribution of energy, we have to add a correction term to $\lambda_{\mathrm{I}}$ so that

$$
\lambda=\lambda_{1}+\lambda_{2} \text {. }
$$

Nevertheless, as Klinger (1973) pointed out this correction can be disregarded and we can take $\lambda=\lambda_{\mathrm{I}}$. A detailed discussion of the choice for the $\tau_{i}$ is given by Klinger (unpublished).

In this work we use only the following expressions:

(I) For umklapp processes:

$$
\tau_{\mathrm{u}}^{-1}=B_{\mathrm{u}} \omega^{2} T \exp \left(-\frac{\theta}{\beta T}\right) .
$$

* There is an error in the paper Klinger (1973). The coefficient before the integral should read

$$
\frac{k T^{3}}{2 \pi^{2} v}\left(\frac{k}{\hbar}\right)^{3} \quad \text { and not } \quad\left(\frac{k}{2 \pi v}\right)\left(\frac{k}{\hbar}\right)^{3} T \text {. }
$$


(2) For scattering on the boundaries of the sample (Casimir, 1938):

$$
\tau_{\mathrm{c}}^{-1}=C,
$$

where $C$ is a constant.

(3) For scattering on point defects, dislocations and microstructures (Klemens, I958):

$$
\tau_{\mathrm{d}}^{-1}=G_{\mathrm{d}} \omega^{R}
$$

with $R=\mathrm{I}, 2,3$ or 4 .

According to Klemens (1958), $R=\mathrm{I}$ corresponds to interactions of phonons with single dislocations. If there are platelets or dislocation loops inserted in an otherwise continuous structure $R=2$. In the case of interactions of phonons with long cylinders inserted into an otherwise continuous structure $R=3$. The interactions of phonons with point defects are described by a term with $R=4$.

\section{Fits of the experimental Results}

We fit the intrinsic part of our experimental results by using the parameters already published by Klinger (1973, unpublished):

$$
\begin{aligned}
v & =2.5 \times 10^{5} \mathrm{~cm} / \mathrm{s}, \\
\Theta & =226 \mathrm{~K}, \\
\beta & =6.5, \\
B_{\mu} & =\mathrm{I} .75 \times 10^{-17} \mathrm{~s} \mathrm{~K}^{-1} .
\end{aligned}
$$

If we limit the phonon mean free path to the size of the macroscopic sample which corresponds to a "Casimir term", $C=4.5 \times 10^{5} \mathrm{~s}^{-1}$, we obtain the ideal curve shown in Figures I, 2 and 6.

In order to fit the extrinsic part of the experimental results we introduce one and only one defect term. It is obvious that it is not possible to give a detailed description of all interaction mechanisms in the real crystal by using this method, but we can see whether there exists a mechanism which is largely dominant. This should be the case when one type of defect term (one value of $R$ ) gives a fit of our experimental results within the limits of the estimated maximum error of our measurements and all the other possible types of defect terms (all the other possible values of $R$ ) do not.

As we consider as "best fit" that giving the lowest mean error, the parameters used could be slightly different from the case where all interaction mechanisms are taken into account.

This is particularly evident when a part of the experimental curve is systematically higher than the calculated curve. It is a fact that all real crystals contain some point defects (isotopic defects, voids, etc.). So a good fit with only one parameter should always be somewhat higher than the experimental points in the vicinity of the maximum. The influence of the presence of point defects is discussed by Klinger (unpublished). In that paper it is also shown that it is impossible to obtain acceptable fits for our experimental results by using a point-defect term $(R=4)$ without using a second defect term. As it is possible to fit all experimental curves presented in this paper in the limits of the estimated maximum experimental error with only one defect term (containing $\omega^{2}$ or $\omega^{3}$ ) it seems meaningless to refine the model.

The heat conduction curves of samples 18 and 19 grown in a teflon vessel can be fitted with $\omega^{3}$; nevertheless the calculated curves are slightly lower than the experimental curve near the maximum (solid curves in Figure I).

The heat conduction curve of sample 2 I grown in a plexiglas vessel can be fitted with a term proportional to $\omega^{2}$ (Fig. 2).

The heat conduction curve of sample 20 grown in a teflon vessel and aged for 9 months and the curve corresponding to sample 15 grown in a plexiglas vessel which had been cooled at $1.2 \mathrm{deg} \min ^{-1}$ and annealed for 12 months are the same for temperatures higher than $3 \mathrm{~K}$. 
So we fitted the common part of them with a term in $\omega^{3}$. In this case the experimental curve is slightly lower than the theoretical curve (Fig. 6).

The parameters used in our fits are given in the following table:

$\begin{array}{ccc}\text { Sample } & R & G_{\mathrm{d}} \\ \text { I } 8 & 3 & 2.18 \times \mathrm{IO}^{-30} \mathrm{~s}^{2} \\ \text { I9 } & 3 & 2.67 \times \mathrm{IO}^{-30} \mathrm{~s}^{2} \\ \text { 20 and I5 } & 3 & 2.34 \times \mathrm{IO}^{-30} \mathrm{~s}^{2} \\ \begin{array}{c}\text { Ihird measurement } \\ \text { 2 I }\end{array} & 2 & 6.4 \times \mathrm{IO}^{-18} \mathrm{~s}\end{array}$

\section{Discussion}

According to Klemens ( $195^{8}$ ) we should have predominance of cylindrical defects in crystals grown in teflon vessels. In the case of crystals grown in plexiglas vessels the interaction of the phonons with cylindrical defects seems to be masked by the interaction with disc-shaped defects becoming the predominant mechanism.

In the first case the coefficient $G_{\mathrm{d}}$ can be expressed as a function of the number of defects:

$$
G_{\mathrm{d}}=\mathcal{N}_{\mathbf{d}} \frac{a^{4}}{v^{2}}
$$

where $\mathcal{N}_{\mathrm{d}}$ is the number of defects per unit area in the basal plane, $a$ the lattice constant and $v$ the velocity of sound.

Using our phenomenological value for $G_{\mathrm{d}}$ we can determine the mean distance between defects as

we find $D \approx 200 \AA$.

$$
D=\frac{\mathrm{I}}{\sqrt{ } \mathcal{N}_{\mathrm{d}}}=\frac{a^{2}}{v} \frac{\mathrm{I}}{\sqrt{ } G_{\mathrm{d}}}
$$

The fact that Davy and Branton (1970) saw cylindrical blocks about $300 \AA$ in size on replicas of ice grown by a different method, indicates that such a cylindrical microstructure should exist in ice from different origins.

The case of parallel disc-shaped defects perpendicular to the heat flux has been treated by Klemens (1958) and Turk and Klemens (1974). For this case Klemens (1958) gives an expression for $G_{\mathrm{d}}$ :

$$
G_{\mathrm{d}}=0.7 \frac{a^{2}}{v} \gamma^{2} \mathcal{N}_{\mathrm{s}}
$$

where $\gamma$ is Grüneisen's constant and $\mathcal{N}_{\mathrm{s}}$ is the number of platelets per unit area; with an estimated Grüneisen constant of 0.65 , a mean distance between the platelets of about $2 \mu \mathrm{m}$ is found.

Truby (1955) studied replicas of etched and nascent surfaces of single ice crystals by electron microscopy. He found a characteristic microstructure of elongated, hexagonal prisms. The small hexagonal units varied greatly in size with an expected width of the order of $3 \mu \mathrm{m}$ and a length of $6 \mu \mathrm{m}$. Truby's results have been confirmed recently by Odencrantz (1973).

$2 \mu \mathrm{m}$ is a good order of magnitude if we suppose that platelets parallel to the basal plane are inserted between the above-mentioned microblocks. The fact that Truby gives a mean value of the length of his prisms three times larger than our distance between the platelets can be attributed to the fact that his crystals were not grown in the same conditions as ours and his mean value is deduced from a limited number of observations. Our value should be the average distance between platelets "seen" by the phonons of the crystal and in this way 
should be the mean value taken over the whole crystal. As the platelets are supposed to be all parallel to the basal plane, and, as Turk and Klemens (1974) explain, the interaction of platelets parallel to the heat flux with the phonons should be negligible, an anisotropy of the heat conduction should occur. As Klinger (unpublished) showed, the difference between two interaction mechanisms $(R=1,2,3)$ is important only at the low-temperature side of the heat-conduction maximum (for temperatures lower than about $7 \mathrm{~K}$ ). Until now no measurements have been done in this temperature range on samples cut perpendicular to the $c$-axis.

Gentile and Drost-Hansen ( 1956 ) explain the formation of the microblocks seen by Truby (1955) by a multiplicaton of dislocation rings by a Frank-Read mechanism followed by a polygonization of the whole crystal. If an equivalent mechanism exists for the submicrostructure seen by Davy and Branton (1970) we could explain why the fit of our experimental curves proportional to $\omega^{3}$ is better for an aged crystal. The polygonization of the crystal is not perfect in a fresh crystal; some dislocation loops persist. In an aged crystal the complete polygonization is achieved.

We found two possible hypotheses to explain the higher concentration of disc-shaped defects in crystals grown in plexiglas vessels:

( I) It could be a mechanical effect: the crystal is grown by lowering the crystallization vessel into a cooling bath of about $248 \mathrm{~K}$. In this way the crystal is cooled down slowly from $273 \mathrm{~K}$ at the growing surface to the temperature of the bath. According to Eisenberg and Kauzmann (1969) the linear heat explansion coefficient of ice is $46 \times 10^{-6} \mathrm{~K}^{-1}$. The manufacturer of the plexiglas, Röhm G.m.b.H., gives a linear heat expansion coefficient of $70 \times 10^{-6}$ $\mathrm{K}^{-1}$. The manufacturer of the teflon, Pampus Fluorplast S.A. Sartrouville indicates an expansion coefficient of $123 \times 10^{-6} \mathrm{~K}^{-1}$. Zarembovitch and Kahane (1964) measured the elastic stiffness $C_{33}$ of ice. They found $C_{33}=1.498 \times 10^{5} \mathrm{~N} / \mathrm{cm}^{2}$ at $257 \mathrm{~K}$.

The elastic stiffness of plexiglas and teflon are given by the manufacturers as $330 \mathrm{ooo} \mathrm{N} / \mathrm{s}$ $\mathrm{cm}^{2}$ and $68000 \mathrm{~N} / \mathrm{cm}^{2}$. Plexiglas and teflon contract more rapidly during cooling than does ice. The radial stress introduced by thermal contraction applied perpendicular to the $c$-axis (which is parallel to the symmetry axis of the cylindrical growth vessels and in this way to the growth direction) could explain the formation of dislocation loops or disc-shaped voids in the basal plane. An estimate of the stress introduced in this way using the constants cited above and the dimensions of our vessels (diameter $6 \mathrm{~cm}$, thickness $0.4 \mathrm{~cm}$ for teflon vessels, diameter $8 \mathrm{~cm}$, thickness $0.2 \mathrm{~cm}$ for plexiglas vessels) shows however that the stress is about two times higher for teflon $\left(\approx 2 \mathrm{~N} / \mathrm{cm}^{2}\right.$ for teflon and $\approx \mathrm{IN} / \mathrm{cm}^{2}$ for plexiglas). So it is not possible to explain the higher concentration of disc-shaped defects in crystals grown in plexiglas vessels in this way.

(2) As plexiglas and teflon are different compounds from a chemical point of view it is not impossible that in the case of plexiglas some impurities which do not fit the crystalline structure of ice are dissolved in the water and trapped in the crystal during growth where they could form disc-shaped inclusions.

More detailed work has to be done in order to clarify this point especially as until now we have not been able to do chemical analyses on crystals grown in plexiglas vessels.

A model proposed by D. Helmreich and W. Steinicke (private communication) can explain the influence of the cooling rate. They observed that the number of Tyndall flowers was higher in crystals that had been cooled down to liquid-nitrogen temperature compared with crystals conserved at $-20^{\circ} \mathrm{C}$. They explain this by an increase of the number of nucleation centres by the following mechanism:

During the cooling voids can migrate and be attracted by dislocations. The voids unite themselves into cavities in order to diminish their surface energy. The decrease of the thermal conductivity after a fast cooling could proceed from such a mechanism. During the tempering big cavities should increase their volume by absorbing small cavities (in tempered crystals the 
number of Tyndall flower decreases). The heat conduction curve for the annealed sample is identical to the curve for a crystal grown in a teflon vessel and annealed during 9 months at temperatures higher than $3 \mathrm{~K}$.

At temperatures lower than $3 \mathrm{~K}$ the heat-conduction curve of the sample made in a plexiglas vessel and cooled rapidly (sample I5, third measurement) falls very steeply with temperature. The existence of large cavities or precipitates of impurities may explain this as shown by Neumaier (unpublished). This could be explained by the fact that voids or, eventually, impurities present in a crystal grown in a plexiglas vessel could have concentrated in a small number of big perturbed zones. In order to estimate the mean size of those zones, measurements of the heat conduction at still lower temperatures are necessary.

Let us summarize our conclusions:

(I) A pure single crystals of ice Ih in its stable state seems to be built up by a hexagonal microstructure some micrometres in width and a sub-microstructure of some hundred of Angströms in width. The length of those microblocks or sub-microblocks in the direction of the $c$-axis should be, according to electron micrographs done by Truby (1955) and Davy and Branton ( 1970 ), about twice the width.

(2) As the length of the mentioned microblocks or sub-microblocks is about twice the width we can consider them approximately as "long cylinders" and apply the mechanism of phonon interaction with the kind of defects described by Klemens (1958). If this mechanism of interaction gives rise to an anisotropy of heat conduction this effect should occur at very low temperatures (at temperatures lower than the temperature where the heat-conduction maximum occurs) where hitherto no heat-conduction data perpendicular to the $c$-axis are available.

(3) When the crystallization vessel is changed (plexiglas instead of teflon) the interaction of phonons with disc-shaped defects becomes predominant.

(4) If such a crystal has been cooled from $258 \mathrm{~K}$ to liquid-nitrogen temperature at a rate of about $1.2 \mathrm{~K} / \mathrm{min}$ and then warmed up at about the same rate and annealed for several months near the freezing point, the above-mentioned disc-shaped inclusions condense into large perturbed centres. The crystal around these centres acquires the same characteristics as the crystals mentioned under (I).

\section{A PROCEDURE TO OBTAIN PERFECT GRYSTALS}

This work offers the possibility for the standardization of ice samples studied in laboratories. In fact the heat-conduction curve is an excellent indicator of crystal perfection. As it is difficult to make heat-conduction measurements, we propose a "quality list" for the growth and handling of artificial ice crystals. To begin with we could take as a basis the following:

(1) Water. Demineralized and double distilled in quartz vessels under nitrogen atmosphere, the crystallizer being filled without contact with ambient air.

(2) Growth. In a cylindrical teflon vessel of diameter $50 \mathrm{~mm}$ or larger by the Bridgman method, growth rate $\leqslant \mathrm{I} .2 \mathrm{~cm} / \mathrm{d}$ or lower.

(3) Ageing. Nine months at least at a temperature between -25 and $0^{\circ} \mathrm{C}$.

(4) Cutting. On a microtome with an advance $\leqslant 0.05 \mathrm{~mm}$ per layer.

(5) Cooling and heating rates. $\leqslant 0.6 \mathrm{deg} / \mathrm{min}$.

We think that such a crystal represents the stable form of a pure Ih ice single crystal. This "quality list" can be modified when sufficient heat conduction data are available for other types of crystals, especially zone-refined crystals and natural crystals. 


\section{Acknowledgements}

Discussions with Dr A. M. de Goer from the Service des Basses Températures du Centre d'Études Nucléaires de Grenoble and with Professor L. Lliboutry, Director of the Laboratoire de Glaciologie in Grenoble are gratefully acknowledged. The author is greatly indebted to Mme Echevin from the Laboratoire de Glaciologie for chemical analyses and to Mme Merlivat from the Centre d'Études Nucléaires de Saclay for analysis of the isotopic impurities in ice samples.

\section{MS. received 30 December 1974 and in revised form 15 April 1975}

\section{REFERENCES}

Ashworth, T. Unpublished. On the thermal conductivity and specific heat of ice. [Paper presented at Symposium on the Physics and Chemistry of Ice, Ottawa, 1972.]

Blicks, H. Unpublished. Protonendiffusion in dotierten Eiseinkristallen. [Dr. rer. nat. thesis, Technische Hochschule, München, 1965.]

Callaway, J. I959. Model for lattice thermal conductivity at low temperatures. Physical Review, Vol. I 13 , No. 4, p. $1046-51$.

Carruthers, P. 1961. Theory of thermal conductivity of solids at low temperatures. Review of Modern Physics, Vol. 33 , No. I, p. $92-138$.

Casimir, H. B. G. 1938. Note on the conduction of heat in crystals. Physica, Vol. 5, No. 6, p. 465-500.

Davy, J. G., and Branton, D. 1970. Subliming ice surfaces: freeze-etch electron microscopy. Science, Vol. 168, No. 3936 , p. $1216-18$.

Dean, J. W., and Timmerhaus, K. D. 1962. Thermal conductivity of solid $\mathrm{H}_{2} \mathrm{O}$ and $\mathrm{D}_{2} \mathrm{O}$ at low temperatures. Advances in Cryogenic Engineering, Vol. 8, p. 263-67.

Dillard, D. S., and Timmerhaus, K. D. 1966 . Low temperature thermal conductivity of solidified $\mathrm{H}_{2} \mathrm{O}$ and $\mathrm{D}_{2} \mathrm{O}$. Pure and Applied Cryogenics, Vol. 4, p. 35-44.

Eisenberg, D., and Kauzmann, W. 1969 . The structure and properties of water. Oxford, Clarendon Press.

Gentile, A. L., and Drost-Hansen, W. 1956 . On the origin of the microstructure in ice. Naturwissenschaften, Jahrg. 43, Ht. 12, p. 274-75.

Jakob, M., and Erk, S. 1929. Die Wärmeleitfähigkeit von Eis zwischen o und $-125^{\circ}$ C. Zeitschrift für Technische Physik, Bd. 10, Ht. 12, p. 623-24.

Klemens, P. G. 1958. Thermal conductivity and lattice vibrational modes. Solid State Physics, Vol. 7, p. 1-98.

Klinger, J. 1973. Thermal conductivity of ice single crystals at low temperatures. (In Whalley, E., and others, ed. Physics and chemistry of ice: papers presented at the Symposium on the Physics and Chemistry of Ice, held in Ottawa, Canada, I 4-18 August 1972. Edited by E. Whalley, S. 7. Jones, L. W. Gold. Ottawa, Royal Society of Canada, p. I $14-16$.

Klinger, J. Unpublished. Conduction thermique et étude des défauts semimacroscopiques de la glace. [D. ès Sc. thesis, Université Scientifique et Médicale de Grenoble, 1974.]

Landauer, J. K., and Plumb, H. 1956. Measurements on anisotropy of thermal conductivity of ice. U.S. Snow, Ice and Permafrost Research Establishment. Research Paper 16.

Lees, C. H. 1905. Effects of temperature and pressure on the thermal conductivities of solids. Part I. The effect of temperature on the thermal conductivities of some electrical insulators. Philosophical Transactions of the Royal Society of London, Ser. A, Vol. 204, No. 12, p. 433-66.

Neumaier, K. Unpublished. Étude des défauts ponctuels et étendus dans LIF par diffusion des phonons. [D. ès Sc. thesis, Faculté des Sciences de l'Université de Grenoble, 1969.]

Odencrantz, F. K. I973. Ice whiskers and the mosaic structure of snowflakes. Fournal of Geophysical Research, Vol. 78, No. 6, p. 958-6r.

Powell, R. W. 1958. Preliminary measurements of the thermal conductivity and expansion of ice. Proceedings of the Royal Society of London, Ser. A, Vol. 247, No. 1251, p. 464-66.

Ratcliffe, E. H. 1962. The thermal conductivity of ice: new data on the temperature coefficient. Philosophical Magazine, Eighth Ser., Vol. 7, No. 79, p. 1197-1203.

Truby, F. K. 1955. Hexagonal microstructure of ice crystals grown from the melt. Fournal of Applied Physics, Vol. 26, No. 12, p. 1416-20.

Turk, L. A., and Klemens, P. G. 1974. Phonon scattering by impurity platelet precipitates in diamond. Physical Review B, Vol. 9, No. Io, p. 4422-28.

Zarembovitch, A., and Kahane, A. 1964. Détermination des vitesses de propagation d'ondes ultrasonores longitudinales dans la glace. Étude de leur variation avec la température. Comptes Rendus Hebdomadaires des Séances de l'Académie des Sciences (Paris), Tom. 258, No. 9, p. 2529-32. 